\title{
Research on the Reliability Level of Backhoe Loaders
}

\author{
Svetozar Madzhov \\ Forest Research Institute, Bulgarian Academy of Sciences, Sofia 1756, Bulgaria
}

\begin{abstract}
This study identifies the main numerical characteristics of the KOMATSU WB93R-5 backhoe loaders reliability indicators, and has examined the durability of assemblies and units, as well as the time for the replacement of the KOMATSU WB93R-5 backhoe loaders' elements. To study the characteristics of the reliability indicators, a methodology for experimental research has been developed, using the complex, comparative and formal method, as well as the systematic, cybernetic and statistical approach.
\end{abstract}

Key words: Reliability, maintenance, R (Repair), assemblies, replacement, backhoe loader.

\section{Introduction}

At the current stage of economic development, the problem of increasing the efficiency of using machines, which are the active part of the basic production funds and determine the production capabilities of the business organization, is especially relevant.

As the technical level of the machines increases, their complexity and productivity increase, the equipment becomes more expensive. For TM (Technical Maintenance) and R (Repair) during the machines lifetime, twice as much money is spent as on their purchase, this ratio being different for different types of machines [1-3]. The main trend, however, is clear - the relative share of the service complex in the overall balance of production means is constantly growing.

A significant cost reduction in the service complex can be achieved by optimizing the structure and parameters of the system for $\mathrm{TM}$ and $\mathrm{R}$ of the equipment with different methods and models. This requires that the numerical characteristics of the reliability indices of the machine components be studied in order to develop an efficient system of maintenance and $\mathrm{R}$, guaranteeing the efficient use of the machines.

Corresponding author: Svetozar Madzhov, Ph.D., assistant professor, main research field: forest mechanization and reliability.

\section{Materials and Methods}

This paper is a continuation of the study of the Komatsu SAA4D104E-1 engine components' life, but now the durability of the backhoe loader's assemblies and units is studied, as well as the replacement time of the KOMATSU WB93R-5 backhoe loader elements.

To study the characteristics of the reliability indicators, authors develop a methodology for experimental research using the complex, comparative and formal method, as well as the systematic, cybernetic and statistical approach.

The complex method was used to evaluate the technical condition of the backhoe loader, the level of reliability of its elements, the internal interconnection of the factors affecting the intensity of the processes which deteriorate the technical condition of the machine. The component's technical condition assessment has been carried out by complex indicators.

The essence of the formal method lies in the construction of models with effective mathematical methods. Models are best suited for analyzing complex systems and making effective management decisions.

The comparative method was used at almost all stages of the study to compare the information obtained and to take into account the influence of various objective and subjective factors on the level of reliability of the study objects. 
The process of occurrence of failures and changes in the state of the study object's elements is random (stochastic), and specific and complex indicators based on statistical information are used to assess the level of elements reliability. Obtaining the statistical characteristics of the indicators is based on the methods of probability theory and mathematical statistics. The systematic approach is applied to select the best solution in the presence of several possible options. Such cases are typical of determining the number of spare parts for the equipment, where there are many acceptable solutions of which the optimal one could be chosen, especially when it comes to allocating a stock of spare parts. The cybernetic approach enables the object under study to be regarded as a system with definite structure, properties, input and output parameters. At the same time, each object is viewed not as an indivisible whole, but as a system of interconnected elements with their properties and quality characteristics. As a result of the system analysis, the best solutions are selected for both the system as a whole and the elements individually.

These methods and approaches will be used in the study of different processes, parameters and models and for drawing up conclusions.

The basic information about KOMATSU WB93R-5 backhoe loaders, obtained through the developed methodology, is classified according to the following basic principles: origin, cause, complexity, type of elements, consequences of failures, nature of manifestation and ways of removal.

The purpose of the study is to determine the basic numerical characteristics of the backhoe loaders reliability indicators, which were the subject of testing using a pre-developed experimental testing methodology.

The study was performed under the conditions in which the machines operate: a set of natural, climatic, production, technical, economic, organizational and social factors affecting the intensity of the change of their state parameters. The survey was carried out for the territory of the Republic of Bulgaria in the head office of Kirov AD in Sofia and Sofia region. The subject of the study was: 180 backhoe loaders operating year-round, and the nominal working fund was 2,128 hours per year; 177 hours per month. The survey was conducted for a period of 4 years during 2010-2014. Authors also have partial information for 2014, but authors will not analyze it at this stage.

The source information was collected at construction companies in southern Bulgaria and includes 39 backhoes. The data collected are from direct observations and information cards from March 2009 until July 2010 and data from business organizations' reports for the preceding six years. The data were collected according to the developed methodology of the experimental study, classified by elements and grouped according to the following classification features, properties and reliability indicators [2, 4-6].

The distribution of failures by reason of the failure occurrence (quality of workmanship; design defects; broken rules of operation; continuous operation; normal wear and tear; quality of R) of the tractor elements is shown in Fig. 1.

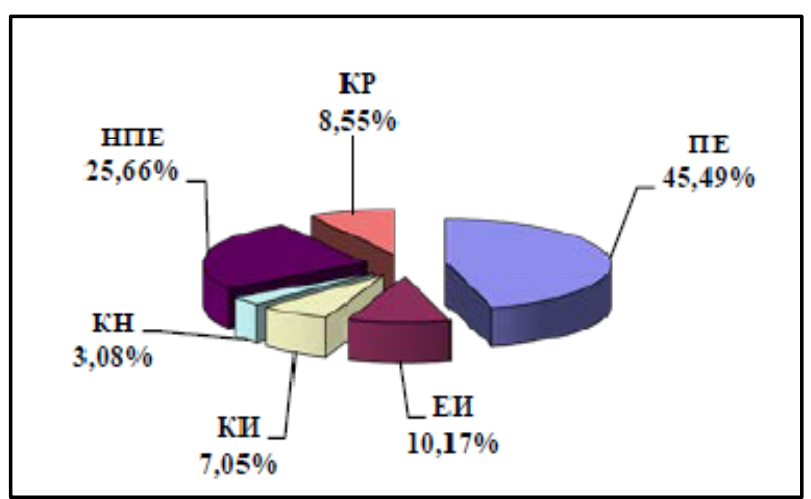

Fig. 1 Distribution of failures by reason of occurrence: ПЕ-continuous operation;

ЕИ-normal wear and tear;

КИ-quality of workmanship;

$\mathrm{KH}$ - design defects;

HПЕ—-broken operating rules;

KP-R quality. 
The reliability information for the KOMATSU WB93R-5 backhoe loaders was collected over a seven-year period, with a number of information collection forms being completed on an ongoing basis over two years of authors' survey. For the previous years, these forms were completed on the basis of accounting documents from the archives of the construction organizations, where for each $\mathrm{R}$ or replacement of an assembly or unit of the backhoe loader it recorded when it was made, how much fuel was consumed, the price of the assembly or unit, who the $\mathrm{R}$ or replacement was performed by, for how long, etc.. This information was collected for 39 excavators in the two areas. The recurrence for most of the elements is on average equal to the number of machines, but there are some elements of tractor units that have not failed, i.e. they are less than 39. Therefore, authors use private methodologies to determine the reliability characteristics of a small sample volume. At the same time, there are items that have failed two or more times, i.e. we have a recurrence greater than 39 .

From the analysis of the types of failures due to their occurrence, authors find that the largest number of failures is due to breakage of parts and units - $56 \%$, and $44 \%$ - due to violation of the regulatory parameters.

\section{Results and Discussion}

The distribution of the failures of KOMATSU
WB93R-5 backhoe loaders in accordance with external manifestation is shown in Table 1.

\subsection{Research on the Durability of Backhoes Units and Assemblies}

The information about the reliability of the elements of the backhoe loader has been processed on the methods of mathematical statistics. The basic numerical characteristics, the parameters of resource allocation of the assemblies and units (exchange elements) of the KOMATSU WB93R-5 backhoe loaders, established on the basis of the experimental study methodology, are given in Table 2, and the gamma percentage resource at $\gamma=80 \%$-in Table 3 , where a simulation modeling technique developed by Kugel [7] and supplemented in the works of Tasev [9], and Mihov [4, 8] was used to determine the basic numerical characteristics of the steering elements [2].

The main numerical characteristics and the law of spare parts requests flow distribution for KOMATSU WB93R-50 backhoe loaders are given in Table 4.

\subsection{Survey on the Time for Backhoe Elements Replacement}

The study and determination of the time for replacement of tractor elements under the conditions of partial mechanization of $\mathrm{R}$ and maintenance work, the basic numerical characteristics and the conditions for replacement of the KOMATSU WB93R-5 backhoe loaders are given in Table 5 .

Table 1 Distribution of failures by external manifestation.

\begin{tabular}{lll}
\hline No. & External manifestation & \% of failures \\
\hline A & Broken parts and assemblies & 28.2 \\
1 & Cam shaft bearing & 11.8 \\
2 & Damage to a gasket tightness & 3.9 \\
3 & Fuel pump & 4.1 \\
4 & Check valve spring & 3.7 \\
5 & Spring of the pusher & 4.2 \\
6 & Regulator connector & \\
B & Incorrect adjustment parameters & 17.1 \\
7 & Increasing feeding unevenness & 12.9 \\
8 & Reducing the minimum cycle feed rate & 8.8 \\
9 & Decreasing the rotation speed and the start of controller activation & 5.2 \\
10 & Decrease in enrichment rate & \\
\hline
\end{tabular}


Table 2 Basic numerical characteristics, resource allocation parameters of KOMATSU WB93R-5 backhoe loaders.

\begin{tabular}{|c|c|c|c|c|c|c|}
\hline \multirow{2}{*}{ No. } & \multirow{2}{*}{ Backhoe elements } & \multicolumn{4}{|c|}{ Estimates of basic numerical characteristics and parameters (liters of fuel) } & \multirow{2}{*}{-Distribution laws } \\
\hline & & top $(a)$ & $\delta(b)$ & $V$ & $c$ & \\
\hline 1 & Gear with reduction & $\begin{array}{l}19,891 \\
(21,538)\end{array}$ & $8,600(2.4)$ & 0.44 & - & B \\
\hline 2 & Gearbox & $\begin{array}{l}21,983 \\
(24,699)\end{array}$ & $\begin{array}{l}10,120 \\
(23,258)\end{array}$ & 0.46 & - & $\mathrm{B}$ \\
\hline 3 & Rear axle & 27,590 & 9,980 & 0.40 & 2,640 & $\mathrm{H}$ \\
\hline 4 & Drive reducer & 26,700 & 2,400 & 0.40 & 8,000 & $\mathrm{H}$ \\
\hline 5 & SU pump & 45,200 & 14,100 & 0.39 & 9,000 & $\mathrm{IM}$ \\
\hline 6 & SU Hydraulics & 42,500 & 15,200 & 0.47 & 10,500 & IM \\
\hline 7 & SU hydraulic str. & 47,200 & 15,600 & 0.44 & 12,000 & IM \\
\hline 8 & Hydraulic pump & 26,950 & 13,000 & 0.48 & 120 & $\mathrm{H}$ \\
\hline 9 & Distribution & 25,900 & 8,800 & 0.41 & 4,700 & $\mathrm{H}$ \\
\hline 10 & Hydro cylinder & 25,200 & 6,200 & 0.30 & 4,600 & $\mathrm{H}$ \\
\hline 11 & Compressor & 26,200 & 10,300 & 0.39 & 250 & $\mathrm{H}$ \\
\hline 12 & Front axle & $\begin{array}{l}16,200 \\
(18,431)\end{array}$ & 8,240 & 0.50 & - & B \\
\hline 13 & Generator & 21,970 & 11,200 & 0.51 & - & $\mathrm{H}$ \\
\hline 14 & Control relay & $\begin{array}{l}13,300 \\
(14,965)\end{array}$ & $6,400(2.1)$ & 0.50 & - & B \\
\hline 15 & Battery & $\begin{array}{l}14,800 \\
(16,780)\end{array}$ & $6,600(2.2)$ & 0.47 & - & B \\
\hline 16 & Starter & $\begin{array}{l}22,350 \\
(25,329)\end{array}$ & $10,480(2.2)$ & 0.48 & - & B \\
\hline
\end{tabular}

Table 3 Gamma-percentage resource of the KOMATSU WB93R-5 backhoe loader elements.

\begin{tabular}{lll}
\hline No. & Excavator element & $80 \%$ gamma-resource, liter \\
\hline 1 & Gear with reducer & 12,800 \\
2 & Gear box & 14,870 \\
3 & Rear axle & 19,900 \\
4 & Drive reducer & - \\
5 & Steering unit pump & 33,900 \\
6 & Steering unit hydraulics & 29,800 \\
7 & Steering unit hydraulic accelerator & 33,800 \\
8 & Hydraulic pump & 27,080 \\
9 & Distributor & 22,700 \\
10 & Hydraulic cylinder & 22,800 \\
11 & Compressor & - \\
12 & Front axle & 9,400 \\
13 & Generator & 13,650 \\
14 & Control relay & 7,800 \\
15 & Battery & 8,900 \\
16 & Starter & 15,900 \\
\hline
\end{tabular}

Table 4 The main numerical characteristics and the law of spare parts requests flow distribution for KOMATSU WB93R-50 backhoe loaders.

\begin{tabular}{|c|c|c|c|c|c|c|c|}
\hline \multirow{2}{*}{ No. } & \multirow{2}{*}{ Backhoe elements } & \multirow{2}{*}{$\begin{array}{l}\text { Number of } \\
\text { workers }\end{array}$} & \multirow{2}{*}{\multicolumn{2}{|c|}{$\begin{array}{c}\text { Replacement time by } \\
\text { standard hours (man hours) }\end{array}$}} & \multicolumn{3}{|c|}{ Replacement time by expert evaluation, hours } \\
\hline & & & & & $\overline{t_{c p}}$ & $\sigma$ & $V_{x}$ \\
\hline 1 & Gear with reducer & 2 & - & - & 4.30 & 1.04 & 0.24 \\
\hline 2 & Gear box & 2 & 3.78 & $(7.56)$ & 9.80 & 1.34 & 0.14 \\
\hline 3 & Rear axle & 2 & - & - & 12.90 & 1.77 & 0.14 \\
\hline 4 & Drive reducer & 2 & - & - & 1.20 & 0.25 & 0.21 \\
\hline
\end{tabular}


Table 4 to be continued

\begin{tabular}{lllllllll}
\hline 5 & SU pump & 2 & 1.55 & $(3.09)$ & 1.60 & 0.69 & 0.43 \\
6 & SU hydraulics & 2 & - & - & 2.80 & 0.54 & 0.19 \\
7 & SU hydraulic accelerator & 2 & 1.55 & $(3.09)$ & 3.80 & 1.26 & 0.33 \\
8 & Hydraulic pump & 2 & 1.92 & $(3.83)$ & 3.10 & 0.96 & 0.31 & 0.25 \\
9 & Distributor & 2 & 2,30 & $(4.60)$ & 3.10 & 0.76 & 0.30 \\
10 & Hydraulic cylinder & 1 & - & - & 0.80 & 0.24 & 0.19 \\
11 & Compressor & 1 & - & - & 1.08 & 0.28 & 0.27 \\
12 & Front axle & 2 & 0.63 & $(1.25)$ & 3.09 & 0.82 & 0.27 \\
13 & Generator & 1 & 0.27 & $(0.27)$ & 0.70 & 0.19 & 0.14 \\
14 & Control relay & 1 & 0.27 & $(0.27)$ & 0.69 & 0.16 & 0.25 \\
15 & Battery & 1 & 0.36 & $(0.36)$ & 0.36 & 0.09 & 0.27 \\
16 & Starter & 1 & 0.30 & $(0.30)$ & 0.95 & 0.26 & \\
\hline
\end{tabular}

Table 5 Replacement time for KOMATSU WB93R-5 backhoe loaders' elements.

\begin{tabular}{|c|c|c|c|c|c|}
\hline \multirow{2}{*}{ No. } & \multirow{2}{*}{ Exchange elements } & \multicolumn{3}{|c|}{ Estimates of basic numerical characteristics, $\mathrm{h}$} & \multirow{2}{*}{-Distribution laws } \\
\hline & & $X_{c p}$ & $\sigma$ & $V_{x}(\%)$ & \\
\hline 1 & Engine & 3.85 & 1.90 & 49.35 & $\mathrm{P}$ \\
\hline 2 & Cylinder head & 1.30 & 1.35 & 103.85 & $\mathrm{P}$ \\
\hline 3 & Nozzle & 12.00 & 3.60 & 30.00 & $\mathrm{P}$ \\
\hline 4 & Fuel pump & 1.46 & 1.18 & 84.29 & $\mathrm{P}$ \\
\hline 5 & Pump supp. & 1.50 & 1.10 & 73.33 & $\mathrm{P}$ \\
\hline 6 & Oil pump & 4.80 & 1.90 & 39.58 & $\mathrm{P}$ \\
\hline 7 & Water pump & 2.00 & 1.50 & 75.00 & $\mathrm{P}$ \\
\hline 8 & Radiator & 0.85 & 0.97 & 114.12 & $\mathrm{P}$ \\
\hline
\end{tabular}

\section{Main Conclusions}

It was found that the highest number of failures was due to breakage of parts and assemblies- $56 \%$, and $44 \%$ due to breach of the regulatory parameters.

The law of spare parts requests distribution for KOMATSU WB93R-5 backhoe loaders, with the Pearson criterion, was determined and the basic numerical characteristics were determined.

The intensity of the request flow for KOMATSU WB93R-5 backhoe loaders by months during the year of use was determined.

It has been found that the time for the backhoe components replacement is within a wide range $(0.36-12.90 \mathrm{~h})$ and this depends on the complexity of the element and the technical equipment with disassembly and assembly devices.

Replacement times were found to be distributed according to the normal distribution law, and the variation rate was in the range of $14 \%-43 \%$.

\section{References}

[1] Kozlovskiy, V. A., et al. 1998. Logistics. Sofia, Bulgaria.

[2] Mihov, M., and Tasev, G. 2012. Machinery Maintenance and Repair. Sofia, Bulgaria, p. 149.

[3] Chervonyi, A., Lukyashtenko, V., and Kotin, L. 1972. Reliability of Complex Systems. Moscow, Russia.

[4] Mihov, M., and Tasev, G. 1990. "Probability Model for Inventory Stocks Management." Agricultural Machinery 8: 87-93.

[5] Skovorodin, V., Tishkin, L., and Tasev, G. 1990. AM Reliability Guide. Sofia, Bulgaria, p. 245.

[6] Spiridonov, G., and Tasev, G. 1981. Some Theoretical and Applied Aspects of the Repair and Maintenance of Agricultural Machinery. Rousse, Bulgaria, p. 336.

[7] Kugel, R. V. 1990. Tractor Operational Reliability. Moscow, Russia.

[8] Mihov, M. 1995. "Study of the Distribution of Inventory Replacement Parts for Tractors." Ph.D. thesis Institute of Soil Science "Nikola Poushkarov", Sofia.

[9] Tasev, G. 2000. "Survey on the Structure and Basic Parameters of the Agricultural Machinery Maintenance System." Sofia, Bulgaria. 